\title{
La historia universal de Cesare Cantú en América Latina
}

\author{
The universal history of Cesare Cantú in Latin America
}

\author{
Hernán G. H. Taboada ${ }^{a}$ \\ E-mail: haroldo@unam.mx \\ https://orcid.org/0000-0002-5769-693X iD
}

a Universidad Nacional Autónoma de México, Centro de Investigaciones sobre América Latina y el Caribe, Ciudad de México, México

\section{RESUMEN}

El historiador italiano Cesare Cantú (1804-1895) gozó de gran prestigio en América Latina desde mediados del siglo XIX hasta las primeras décadas del XX. Ello es particularmente cierto de su Historia universal (obra que empezó a publicar desde 1838), un trabajo basado en el esquema cristiano de la historia que carece de gran originalidad, pero que, en contrapartida, es rico en información. En este artículo se explora su amplia presencia en las bibliotecas particulares, el carácter de modelo que revistió, su función como fuente principal de información y de opiniones y algunos de los juicios que mereció de parte de historiadores, escritores o políticos, sobre todo católicos, pero no en su totalidad. Desde los años finales del siglo XIX, la popularidad de Cantú empezó a decaer, en parte debido al aumento de la información histórica y sofisticación historiográfica de la intelectualidad latinoamericana. Se presentan también algunos ejemplos de esa pérdida de prestigio.

\section{PALABRAS CLAVE}

Historiografía del siglo XIX; História universal; Catolicismo

\section{ABSTRACT}

Italian historian Cesare Cantú (1804-1895) was held in great regard in Latin America from the middle 19th century until the first decades of the 20th. This was particularly true for his Universal history (that began appearing from 1838), devoid of originality but full of information and based on the Christian interpretation of history. This article explores its widespread presence in personal libraries, its model character, its function as a chief source of historical facts and opinions, and some of the opinions given by historians, writers or politicians, mostly - but not only - Catholic. The work's popularity began to fade by the final years of the 19th century, in part due to the growth of historical information and historiographical sophistication among Latin Americans intellectuals. Some examples of this loss of prestige are also presented. 


\section{İntroducción}

En mis recorridos por librerías de ocasión en Buenos Aires, hace ya muchos años, todavía alcanzaba a ver colecciones o tomos sueltos, algunos ya deteriorados, de la Historia universal de Cesare Cantú, en su traducción al castellano. Nunca se me ocurrió hojearlos y sólo lo he hecho últimamente tras percatarme de que el historiador lombardo gozó de gran fama y prestigio en España y en América Latina durante muchas décadas. Fueron, en efecto, muchas, porque él vivió entre 1804 y 1895 y aquella obra era, por ende, ya veterana cuando se hizo popular. Y, más, no fue la única con que logró prestigio entre nosotros, como resultado de la circulación de sus ideas, como fui comprobando al encontrarme con citas, referencias, elogios y paráfrasis de la obra de Cantú en páginas de los autores latinoamericanos más heterogéneos en cuanto a época, lugar y tendencia. Tal cuantía me llevó a pensar que no sería mala idea rastrear las etapas de la marcha triunfal por nuestros países de aquel monumental repertorio decimonónico desde sus inicios de fama y prestigio hasta su crepúsculo y posterior olvido en el siglo $x x$, cuando los saldos de una bodega o la venta de una biblioteca lo arrojaban a esperar desde los estantes de alguna librería la llegada de un incauto cliente.

\section{Vida, gloria y escritos}

Estuvo Cesare Cantú rodeado de una fama de genialidad emanada de su incesante producción de libros, que llegaron a alcanzar la cifra de unos 500, sobre asuntos históricos, literatura italiana, memorias sobre Alessandro Manzoni, sobre el Concilio Vaticano, incluyendo una guía turística, poemas, novela histórica, biografías y relatos edificantes, materiales que, además, individualmente, a veces sumaban varios volúmenes. Escribir no fue su única tarea: se hizo cargo de sus 10 hermanos desde temprana edad, daba clases ya a los 18 años, fue parlamentario y periodista, organizó una tertulia erudita, tradujo a historiadores 
extranjeros, proyectó colecciones, dirigió el Archivio di Stato de Milán. Viajaba, se carteaba con personajes de vario fuste. Es obvio que trabajaba mucho y eso atestiguan quienes lo visitaban. No se casó y vivía en Milán con las familias de sus hermanos.

Entre tan vasta labor sobresale la mentada Historia universal, de aparición oportuna en una Europa firmemente encaminada a la hegemonía mundial y que empezaba a manifestar su preferencia por los panoramas generales. Estos habían estado ausentes largo tiempo de la historiografía, pero reaparecieron cuando, en el siglo xviII, se redactó en Inglaterra una Historia del mundo, con la colaboración de varios eruditos, y otras se escribieron durante las décadas siguientes en Alemania y Francia (FLORESCANO 2012; HARBSMEIER 1989; MELO ARAÚJO 2018; PASAMAR 2008; STUCHTEY; FUCHS 2003). No era, por ende, Cantú el primero que acometía la empresa de contar toda la historia humana desde sus inicios y él mismo cita numerosos antecedentes en su introducción general.

Sin embargo, su obra fue la primera de su tipo ideada en la Italia moderna, donde ya se habían traducido varias historias universales alemanas, lo que demuestra que el tema suscitaba interés. Por otro lado, constituía obra unitaria y no compilación de diversos autores, sus dimensiones la hacían más completa que otras y su hacedor tenía talento comercial, interés en los derechos de autor, amor al dinero y sagacidad, junto con su editor Pomba, para aprovechar el creciente mercado de las clases medias ofreciéndoles el panorama de los siglos en un estilo ameno, ilustrado con abundancia de anécdotas, agregándole cierto tono moralista y católico, pero mezclado con su liberalismo italiano y su creencia en el progreso, valores expresados en máximas que todavía circulan. ${ }^{1}$ El McGuffey de Italia, así se lo llamó. Concluidos en italiano entre 1838 y 1846, los primigenios 35 volúmenes se sometieron posteriormente a revisiones y agregados $y$ aparecieron en ediciones y traducciones numerosas al francés,
1 Bastante convencionales: "Gasta siempre una moneda menos de lo que ganes", "Uno no se hace grande más que midiendo la pequeñez de su dolor", "El pan más sabroso y la comodidad más agradable son las que se ganan con el propio sudor", "La peor prodigalidad es la del tiempo" (muy acorde con su carácter), "Cuantas menos necesidades sintáis, más libres seréis", "El destino de la humanidad es progresar padeciendo". 
inglés, alemán, lenguas escandinavas, húngaro, polaco, catalán, portugués y castellano (BERENGO 1975; FINCH 1886; MAZZONI 1930).

Estas últimas traducciones nos acercan al tema ya tocado de su popularidad en nuestros países, confirmada por sus vicisitudes editoriales. La Historia universal fue vertida al castellano por Antonio Ferrer del Río y publicada entre 1847 y 1850 , es decir, inmediatamente, aunque parece que de forma descuidada, con libertades y agregados frecuentes (GONZÁLEZ SUÁREZ 1892). Una segunda traducción -cuya existencia nos habla de las posibilidades comerciales que se le veían a la obra - estuvo a cargo de Nemesio Fernández Cuesta (amigo y socio del venezolano Rafael María Baralt, residente en España). Le siguieron 21 ediciones: seis de un compendio y 13 de la obra completa hasta 1927 (y contando sólo las legales). En general, la obra se editó en España, pero, entre 1851 y 1853, la traducción de Ferrer del Río apareció en México como parte principal de un vasto proyecto editorial. He visto también pies de imprenta de Buenos Aires. Las sucesivas ediciones se presentaban con continuaciones, con complementos para nuestros países. Había impresiones en gran formato, con tapas duras, papel satinado, grabados a fuego, guardas, marcadores de seda e ilustraciones de Gustave Doré; y otras más pequeñas, en rústica y sin grabados. Entre las primeras destacó la de la editorial Garnier, muy activa en América Latina, con la traducción de Fernández Cuesta. En portugués, la História universal fue vertida a partir de la edición francesa de $1867 .^{2}$ Aunque estuvo a cargo de un reconocido escritor y diplomático, embajador portugués en Río de Janeiro, se trató de una edición pirata o por lo menos no aprobada por el autor, no obstante lo cual circuló por Portugal y Brasil. ${ }^{3}$ Otras obras de Cantú, que en cierto modo continuaban la Historia universal, fueron también traducidas: además del compendio que ya cité, obras menores que destacan (ya se verá por qué) son la Historia de cien años (1852) y Los últimos treinta años (1882) (MILLÁN DE BENAVIDES 2010). Hasta los versos de Cantú hallaron traductor.

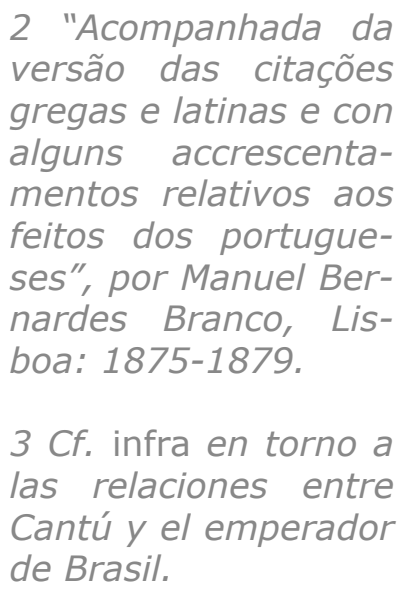
de Brasil. 
Abundan las noticias sueltas sobre la circulación de la Historia universal, las que empezaron a alertarme sobre la utilidad de rastrearlas: "tan conocida y tan justamente apreciada en las repúblicas hispano-americanas", comprobaba el padre Federico Suárez González, acucioso historiador del Ecuador, aunque también suponía que, con sus volúmenes lujosos, grandes e inmanejables, las editoriales españolas, conocedoras de la índole de sus compatriotas, las habían hecho más para adornar bibliotecas que para ser leídas (GONZÁLEZ SUÁREZ 1892). Su publicación fue prevista en los iniciales proyectos editoriales mexicanos; figuraba en las bibliotecas de artesanos de Bogotá (LOAIZA CANO 2009, p. 47). En dicha ciudad, "apenas hay casa donde no suene un piano y donde no se vea un ejemplar de Cantú", aunque cueste 30 o 40 pesos, decía Miguel Antonio Caro, para contrastar con los libros del impío Ernest Renan, baratos pero que no se vendían (según decía) (CARO [1882] 1962, p. 963). "En las viejas casonas criollas abundan los estantes con obras de Courcelle Seneuil, de Leroy Beaulieu, de César Cantú, revueltos con tratados de lechería, veterinaria, derecho internacional y hacienda pública. Añorando esos textos y esos tiempos aún viven muchas gentes" (LATCHAM 1930, p. 149). "Era algo como el retrato de familia y figuraba en las bibliotecas privadas junto al Año Cristiano y la Historia general de España de Lafuente" (REYES [1918] 1958). Se encuentra entre los libros que el arrepentido prestador de libros de cierta crónica de Juan León Mera ya no vuelve a ver: "mira ese andamio, no hace mucho que estaba lleno con la Historia universal de César Cantú" (MERA [1862] 1903).

Y llegaba lejos: recordaba Alfonso Reyes que su padre, el coronel Bernardo Reyes, había aprovechado sus ocios en Monterrey "nada menos que para reunir de un rasgo los incontables volúmenes de la Historia de la Humanidad de César Cantú. Toda empresa habría de ser titánica para contentarlo y estimularlo" (REYES [1930] 1990, p. 32). Significativo fue el hallazgo del italiano Giovanni Pelleschi cuando exploraba el Gran Chaco en el norte argentino: allí encontró, en la nutrida biblioteca de otro coronel, destinado a Fuerte Sarmiento y como único 
autor italiano, a César Cantú, representado por su Historia universal en bella traducción. Y agregaba con satisfacción el explorador que la obra de su compatriota se hallaba en todos los rincones de la Argentina gracias a la red de bibliotecas públicas establecida por Domingo Faustino Sarmiento (PELLESCHI 1886, p. 198-199).

Tal ubicuidad la convirtió en referencia de la cultura de las clases medias y como tal aparece en la tragicomedia chilena titulada precisamente La historia universal de César Cantú (1890) (SUBERCASEAUX 1992, p. 45). En muchas casas oficiaba de adorno, de acuerdo, pero también hay muestras de que la obra era leída, de que era autoridad para las noticias más dispares, fuente para una argumentación sobre terrenos baldíos, sobre la decadencia de Roma, para un elogio del poeta Lucano, del sánscrito o de la lengua árabe (DIHIGO y MESTRE 1932, p. 13; KURBAN 1933, p. 161; MOLINA ENRÍQUEZ [1909] 1978, p. 208); y aun se creía que Cantú podía ser un maestro de método (LARRAINZAR 1992 , p. 152, 156 y 159). Se lo adoptó como tal en intentos historiográficos criollos, como el del venezolano Juan Vicente González, autor de un Manual de historia universal para cuya elaboración utilizó como fuente a distintos autores europeos, "poco satisfecho con Cantú, aunque vasta enciclopedia histórica" (GONZÁLEZ 1863, p. vii). Otro venezolano, Felipe Larrazábal, de amplia obra, dejó al morir en un naufragio en 1873 el manuscrito de una historia universal "según el plan de la de César Cantú, con quien había estado en constante correspondencia" (CORTÉS 1875).

Cantú era mencionado en discursos, figuraba en la prensa diaria, se colocaban frases suyas como epígrafe o simplemente se disfrutaba de su lectura: "felices quienes tienen la gloria de leer a Thiers, a Michelet, a Cantú, a Luis Blanc, a Prescott, a Lamartine" (José María Samper); "uno de mis gratos entretenimientos fue siempre la lectura; el primer mueble que tuve fue un estante para libros. Chateaubriand, César Cantú, Thiers, Madame de Stael eran mis autores favoritos" 
(Vicente Restrepo). Nótese por quiénes estaba acompañado en estos recuentos. Semejantes apreciaciones se encuentran en Soledad Acosta de Samper o Juan Montalvo. Era típica lectura de juventud: estaba en la peruana biblioteca del abuelo de Víctor Andrés Belaunde (BELAUNDE 1967, t. 1, p. 152 y 202); lo leía el chileno Francisco A. Encina (1954, p. x); aburrió, cuando niño en Torreón, a Julio Torri (CARBALLO 1986, p. 169); en cambio, tras haberlo frecuentado en sus años mozos, José de la Riva-Agüero "sabía de memoria páginas enteras de César Cantú, historiador italiano entonces en boga" (RIVA AGÜERO [1905] 1962, v. 1, p. 251; GARCÍA CALDERÓN [1949] 2003, p. 197).

También servía en los programas escolares, en planes de difusión de la lectura: en las bibliotecas populares de Sarmiento, donde Pelleschi lo halló, en los cursos de Historia Universal en Nicaragua (MOLINA ARGÜELLO 1953, p. 114), en Ecuador, México y Bolivia. Desde este último país, confesaba Alcides Arguedas cómo, abrumado ante la encomienda escolar de disertar sobre la historia, "resolví por primera vez en mi vida aprender de memoria los pasajes salientes de la introducción de César Cantú, seleccionando a mi arbitrio, es decir, las partes más vistosas y de más brillante hojarasca. La recitación resultó pasable, pues la hice de un tirón, como un papagayo"; el maestro lo felicitó y le auguró (acertadamente) que sería historiador (ARGUEDAS 1959, t. 1, p. 630-631). Años antes, el niño Federico González, el que después acusaría a las familias criollas de comprar al Cantú como adorno, lo había leído ávidamente, en su totalidad, a pesar de que un maestro jesuita lo había calificado de obra mediocre, de mera consulta:

Cuando Cantú pudo escribirla, les repliqué yo, ¿por qué no he de poder leerla yo? iY la leí, y la estudié, y recibí una impresión profunda con la lectura y con el estudio de semejante obra! César Cantú me hizo comprender lo que convenía que fuera la Historia, considerada como una ciencia de moral social (GONZÁLEZ SUÁREZ 1969, p. 157-158). 
Es decir que el lombardo influyó poderosamente sobre la posterior obra del eclesiástico ecuatoriano (valiosa). También lo hallamos en la introducción que Mariano Felipe Paz Soldán antepuso a su libro sobre el Perú independiente, donde es citado como autoridad en cuanto a método y reflexión histórica, al lado de Tácito, Michelet o Sismondi (PAZ SOLDÁN 1868, p. iv y siguientes). El mismo carácter de modelo tuvo para la Historia eclesiástica, política y literaria de Chile (1850), de José Ignacio Víctor Eyzaguirre, para el Bosquejo de la historia militar de Venezuela (1855), de José de Austria, para la historia del golpe contra Santa Anna de Anselmo de la Portilla (1856), para Pedro Francisco de la Rocha en su "Estudio de la historia de la revolución de Nicaragua" (1874) y para la Historia de Colombia, de Jesús María Henao y Gerardo Arrubla (1911). En muchísimos trabajos más, esté o no mencionado, suministraba el decorado de fondo. Componiendo un alegato sobre el doctrinarismo y la libertad, el colombiano Felipe Pérez, para no perder tiempo en asunto fútil como los datos de base, "ha tomado la Historia universal de César Cantú, la ha abierto sobre su pupitre y, pluma en mano, la ha extractado, y a veces la ha copiado al pie de la letra sin citarla", comprobaba ser un adversario ofreciendo de ello evidencia clarísima (MERCHÁN 1886).

Tales lectores se deshacían en elogios a veces disparatados: "el más grande de los historiadores modernos", escribía el chileno Benjamín Vicuña Mackenna, cuya apreciación compartieron muchos: "el primer historiador del mundo, César Cantú" (el colombiano José Manuel Groot); "el ilustre Cantú", "figura acaso la más eminente entre contemporáneos, en el orden literario y científico" (el también colombiano Miguel Antonio Caro); el "doctísimo historiador César Cantú" (el mexicano Ignacio Ramírez); "el gran Cantú", para Benjamín Sánchez, que en la provincia argentina de San Juan escribía hacia 1899 sobre filosofía de la historia (CARO [1882] 1962, p. 963; GROOT 1876, p. 70; RAMÍREZ [1905] 1988, v. 6, p. 215; ROIG 1970, p. 179; VICUÑA MACKENNA 1856, p. 284-285). 


\section{Un público latinoamericano}

Se habrá visto que, entre los seguidores, plagiarios o panegiristas citados, abundan los católicos: Federico González era sacerdote y Eyzaguirre también; católicos moderados eran Acosta de Samper, Montalvo y Sánchez y furibundos, Groot y Caro. El italiano ofrecía en efecto un panorama acorde con sus creencias: el mundo tenía cuatro mil años de edad, su historia iniciaba con la Creación, sobre Jesucristo exponía una versión que podía utilizarse contra la de Ernest Renan (y una réplica colombiana contra éste se basó en Cantú, junto a otras autoridades), así como también ofrecía argumentos contra páginas irrespetuosas de Edward Gibbon y se explayaba sobre vidas de santos que debieron de ser populares. La Inquisición había sido para él un "verdadero progreso" y defendía a la Iglesia católica en asuntos como la Reforma o el juicio a Galileo.

De esa forma, suministraba un sustituto aumentado y puesto al día de la vieja historia universal de Bossuet (1681), que había gozado de mucho prestigio en nuestra América desde la Colonia hasta bien entrado el siglo xIX como síntesis comprensiva. Cuando ya era evidente que la cobertura cronológica y geográfica del obispo francés era estrecha y, sobre todo, que había sido superada por el aumento de la información y las nuevas visiones del mundo, apareció la obra del lombardo, cuyo carácter confesional, muy fácil descubrir, se señalaba a menudo y llegó a provocar una respuesta protestante.

Sin embargo, en otro parecido con Bossuet, Cantú gozó de un público que fue más allá del católico y tuvo seguidores de tendencia liberal y laica, como ciertos nombres de admiradores dejan ver. Ello debido a que fue también, repito, liberal y patriota italiano y, como tal, tuvo diferencias con el Vaticano en relación con la anexión de Roma por el Estado italiano y con otros asuntos menores. Reiteraba su equidistancia en cuanto a esas tendencias $y$, si bien se le criticaron ciertos remilgos 
religiosos, cuando apareció la edición mexicana de 1851 de la Historia universal (producto de una editorial conservadora, por lo demás), las suscripciones fueron abundantes.

Contribuían a su éxito atractivos adicionales: su amplitud, su extendida fama, sus dotes de expositor y cierto carácter acomodaticio, así como el hecho de que, a diferencia del cerrado exclusivismo eurocéntrico de otras historias universales, la de Cantú dio lugar a los pueblos orientales (SCHWAB 1950, p. 134), en tratamiento que hoy vemos disparejo pero que, para la época, era excepcional en una obra para el gran público. Complementaba esto con otro mérito análogo que le dio gran prestigio en nuestros países: también a diferencia de la mayoría, Cantú prestó atención a España y al mundo hispanoamericano. Podríamos ver aquí otro ejemplo de su indiscriminado almacenamiento de toda fuente que encontraba al paso, pero había también alguna tradicional atención a nosotros en el liberalismo italiano (FILIPPI 1986) y él personalmente tenía en ello intereses confesionales y editoriales. Leía el castellano, como varias otras lenguas, y, al parecer, también lo hablaba, ya que viajaba a menudo a España.

Se las ingeniaba de este modo para allegar bibliografía, exhibida en notas al pie que acá y allá revelan títulos sobre nuestros asuntos, aprovechados en páginas y capítulos en torno al origen del hombre americano, las civilizaciones precolombinas, el descubrimiento, la evangelización y la administración colonial, algunos desarrollos políticos recientes $y$, tema especialmente grato, las luchas de independencia. No sólo daba información que en otras partes no se hallaba, sino que lo hacía en un tono que nos era agradable: elogioso de las civilizaciones azteca e inca y de nuestras riquezas y progreso, crítico del gobierno español y portugués, pero en tono de ecuanimidad que podía agradar a hispanistas y antihispanistas. Al hablar de Bolívar, y aunque no con completo encomio, ${ }^{4}$ le daba un espacio que era raro encontrar entonces (CANTÚ 2005).

\begin{abstract}
4 "Simón Bolívar imitó a Washington en el vencer $y$ organizar, sin más ambición que la de libertador"; "Si Bolívar tenía el genio de la guerra, no poseía el de la legislación". El venezolano Rufino Blanco-Fombona retomaba con satisfacción la traducción francesa de Cantú en la que el autor afirmaba que el liberalismo, derrotado en Europa, era salvado en América por Bolívar (véase el comentario a la vida de Bolívar de Felipe Larrazábal en Blanco Fombona (1981, p. 407)); en relación con el famoso artículo de Marx sobre Bolívar, se ha notado el desconocimiento general que imperaba entonces en Europa, con excepciones entre las cuales se cuentan Humboldt, Goethe, Carlyle y las historias universales de Gervinus y Cantú (véase ARZE 1998, p. 130-131).
\end{abstract}


Él advertía que "poco nos aventuramos en hablar de unos países que no nos son mejor conocidos de lo que lo fueron los germanos en tiempo de Tácito". Prueba de dicha ignorancia ambiental es el trozo de cierta presentación suya "A los lectores": "Las adiciones hechas en las ediciones españolas y portuguesas publicadas en Europa y en América son tan escasas que no han podido servirme, ni como auxiliares, en la nueva obra". También se quejaba de que esos textos no habían seguido su método,

según el cual, la manera de fijarse sobre las particularidades características de los hechos se amalgamaba con la ciencia de las miras completivas, y se seguían todas las manifestaciones de la actividad humana, teniendo siempre en cuenta el progreso de la humanidad, considerada como una sola familia (CANTÚ 1881, p. 109; CANTÚ 1879, Introducción "A los lectores").

Tales palabras nos dan idea de su estilo y del de sus traductores, pero no convencen de sus dotes de síntesis: plenamente se exhiben los defectos de los métodos de búsqueda y escritura de Cantú en las páginas que nos dedica. Nos topamos con información dispareja, vaga, errónea, amontonamiento desordenado de nombres, fechas, datos estadísticos, juicios y comparaciones, nombres mal escritos, falta absoluta de perspectiva. La bibliografía que cita es errática, evidentemente la que le llegaba a mano, no vemos algunos grandes nombres de las historiografías nacionales, que ya existían, y vemos muchos otros que nada nos dicen. De fuentes originales, carencia absoluta.

Pese a todo, cierto orgullo debía suscitar que nos mencionaran en libros provenientes de la culta Europa y Cantú llegó a sernos fuente de conocimientos sobre nosotros mismos: José Antonio Páez, caudillo de la independencia y presidente de Venezuela, al hablar del Congreso de Panamá, lo hacía reproduciendo varias páginas de Cantú (PÁEZ s.f., p. 298 y ss.). La versión que atribuye a los incas los principios de "no robes, no seas ocioso, no mientas", que 
probablemente se originó en el siglo XIX, se difundió gracias a Cantú, que la incluyó en su panorama de la civilización inca y la siguen repitiendo hasta hoy los indigenistas (CERRÓN-PALOMINO 2011; VEGA 2012). Al componer su novela María hacia 1865, Jorge Isaacs introdujo en varios capítulos la historia de los africanos Nay y Esther en sus desgracias por África y Colombia, apuntalando su narración con citas de la Historia universal de Cantú que le habían sido proporcionadas por Miguel Antonio Caro (HENAO RESTREPO 2005, p. 21).

César Cantú: el nombre españolizado, de acuerdo con las normas de entonces, nos llegó a ser familiar; subsisten calles que lo recogen (en Ciudad de México, Guadalajara, Ambato, São Paulo, Valparaíso, Montevideo, Buenos Aires). El apellido Cantú, originado en una aldea del valle de Como en la alta Italia, llegó en algún momento a México y me ha parecido, por las entradas de Internet, que varios de sus portadores le antepusieron el nombre de César para recordar en sus vástagos a tan ilustre tocayo. Todo reitera la amplia fama e influencia de un historiador hoy poco conocido.

\section{Contactos, correspondencia y polémica}

La inclusión de aquellas noticias y opiniones sobre nosotros podía deberse al fino olfato de Cantú para el público, se dirá, al deseo de agradarnos e impulsar la venta de las tempranas traducciones castellana y portuguesa, pero había un interés más de fondo. El catolicismo de Cantú lo llevaba a observar con interés ciertos desarrollos en América Latina. Aquí llegaron algunos que lo habían tratado: José María Le Gohuir Raud (1871), jesuita bretón que se instaló en Ecuador y sentó plaza entre los historiadores conservadores; el español José Román Leal, que polemizó con él (ya lo veremos), pero con orgullo contaba haberse cruzado en su camino. En Buenos Aires y zonas aledañas residió un tiempo Gustavo Minelli, hacia los años de 1860, que había conocido a Cantú en Italia, y enseñó entre nosotros historia universal, sobre la cual publicó un libro, 
aunque de tono ateo, ajeno por ende a la enseñanza del maestro. También en Buenos Aires desembarcó en 1893 Clemente Ricci, antiguo alumno del Instituto Histórico dirigido por Cantú en Milán (CAVRIANI 2010; DEVOTO 2006, p. 301; GUIANCE 2011, p. 29), quien impartió historia antigua y medieval y desarrolló amplia obra sobre historia de las religiones (aunque también se apartó de Cantú por tener una tendencia más bien racionalista). El abuelo materno de la historiadora mexicana Ida Rodríguez Prampolini había sido, antes de llegar a México, ayudante de Cantú, motivo adicional para que también en su biblioteca familiar figurara la Historia universal (RODRÍGUEZ PRAMPOLINI 2003).

En otros casos, eran autores latinoamericanos los que lo buscaban, le escribían, le mandaban sus obras y algunas citas a pie de página de su obra puede deberse a tales favores (sus títulos aluden a publicaciones muy locales, como compendios estadísticos o ciertos Ensayos sobre la historia de Bolivia, de Manuel José Cortés). Él a veces contestaba y hay testimonio orgulloso de ello de Felipe Larrazábal, cuando preparaba su historia universal. Luis Desteffanis, catedrático de Historia Universal en Uruguay, italiano de origen, mantenía correspondencia con Cantú, al que elogiaba pese a remarcar sus diferencias (ODDONE 1959, p. 20; DESTEFFANIS, 1885, p. 460). El chileno José Victorino Lastarria hacía notar que su obra había sido descuidada por sus coterráneos a pesar de la aprobación europea de Quinet y Cantú (LASTARRIA [1843] 1909, p. 6), quien en efecto lo citaba.

Hasta había encuentros personales en los que, astutamente, Cantú aprovechaba para inquirir: cuando Benjamín Vicuña Mackenna lo fue a ver en Milán, el italiano evitaba las menciones a su labor historiográfica $y$, en cambio, "se empeñaba solamente en obtener de mí algunas noticias sobre el estado de la naciente literatura de mi país" (VICUÑA MACKENNA 1856 , p. 285). Hay por lo menos otros tres nombres que cuentan entre aquellos que fueron impulsados por la manía latinoamericana de visitar a los hombres célebres: "En Milán
5 La frase es de Víctor Eduardo Caro, hijo de Miguel Antonio (18771944), en su autobiografía Bajo el alero (1964) y está citada en Moreno (1983, p. 92). 
conversé con César Cantú, en París compartí un pan con Verdi, y en Roma fui acariciado por León XIII". ${ }^{5}$ "Un señor chileno me contó hace poco, en Lima, que estando en Italia fue a visitar a Cesare Cantú (cuya Historia Universal lo ha convertido en el escritor moderno italiano más conocido en Perú y en el resto de América Latina), para expresarle su admiración" (PEROLARI MALMIGNATI 1882, p. 8). Lo visitó también otro chileno, Abdón Cifuentes, historiador católico. ${ }^{6}$

El más ilustre conocido suyo fue el emperador Pedro II de Brasil. Durante sus recorridos por Europa, éste recorrió Milán acompañado por Cantú, quien fue a buscarlo a la estación de trenes y le presentó a Alessandro Manzoni. Al compilar sus reminiscencias del novelista, Cantú dejó constancia de ese encuentro. En Los últimos treinta años, llamó a Don Pedro II "el más antiguo y el más culto e instruido entre los príncipes reinantes" y tuvo intercambio epistolar con él, de la cual ha quedado un lote de siete cartas: el historiador le manifestaba su admiración, agradecía las atenciones recibidas (hasta una medalla imperial) y, posteriormente, acusó a los militares que lo habían destronado. Entre una cosa y otra aprovechó para criticar la traducción portuguesa no autorizada de su obra, que circuló de todos modos en Portugal y Brasil (OSIO 2005, p. 106).

Otro ilustre fue el ecuatoriano Juan Montalvo, católico, quien envió a Cantú sus Siete tratados, gesto bastante usual entre escritores latinoamericanos que buscaban el reconocimiento de las lumbreras europeas, pero, en este caso, a diferencia de otros, Cantú le contestó (22-Ix-1883) de forma humilde y elogiosa: ningún título tenía para recibir el regalo precioso de los Siete tratados, obra conocida en Italia, así como El buscapié, que había sido traducido al italiano. Y sobre la historia de América y su tema principal, el de los héroes de la emancipación, reconocía Cantú la autoridad de Montalvo, en cuyo escrito "se puede beber como en fuente de gran caudal y que abundan en él hechos y conceptos pertenecientes a los últimos sucesos de América"; remataba aseverando que Montalvo "honra a la
6 Larios Mengotti (2011); revisé las Memorias de Cifuentes, que incluyen noticia de sus viajes por Italia, pero no encontré lo de la visita a Cantú. 
patria y al género humano" (Véase la carta en MONTALVO ANTE SUS ADMIRADORES EXTRANJEROS 1911, p. 27-28). Tras este intercambio, Montalvo visitó a Cantú en Madrid, donde también encontró a Edmondo De Amicis, y recordaba en sus escritos la valoración recibida (MONTALVO s.f., p. 27-28). Hoy Montalvo es justamente celebrado por su estilo y ciertas ideas, pero a nadie se le ocurriría darle un puesto como historiador, lo cual nos instruye sobre los criterios de Cantú para elegir fuentes.

Otro caso del que se pueden extraer enseñanzas es el del colombiano José María Torres Caicedo. En varios de sus libros hay prólogos de Cantú ${ }^{7}$ y éste asentaba, en Los últimos treinta años, que, "si las Repúblicas de la América española enviaran siempre como sus representantes diplomáticos hombres tan eminentes como el Sr. Torres Caicedo, adquirirían prontamente el crédito y estimación que merecen entre los pueblos civilizados de Europa". Los maldicientes de la época nos dicen que Torres Caicedo era un oportunista hábil en relacionarse con gente de renombre en Europa; a ello se pueden deber, entonces, los prólogos y elogios. Pero hay más: si por algo trascendió el nombre de este colombiano es por haber sido uno de los primeros en hablar de "América Latina" (1862), término que Cantú tempranamente usa y que nos acerca al episodio saliente de su relación con nuestros países.

Explicando mucho de su interés erudito, su abordaje giraba en torno de la invasión francesa a México y remontaba a cierta adhesión suya al proyecto de crear un virreinato italiano dependiente del imperio austriaco, que estaría bajo el gobierno del archiduque Maximiliano de Habsburgo (ORSI 1895; BERENGO 1975, p. 340). No prosperó el esquema, pero Cantú se convirtió en profesor y amigo personal de Maximiliano, y a éste, años después, las circunstancias lo llevaron a ser no virrey, sino emperador, no de Italia, sino de México. Desde un principio vemos a Cantú involucrado en la empresa, descubrimos su firma en el prólogo a la edición italiana de México antiguo y moderno (1863), de Michel Chevalier, obra considerada como instrumento ideológico de la invasión y con la cual se muestra
7 Tratándolo de arribista, un enemigo denostaba sus libros "precedidos de cartas con abstractos $y$ vagos encomios de César Cantú" y otros. Véase GARCÍA ORTIZ 1932 , p. 27. 
Cantú conforme (CANTÚ [1864] 1878). Luego siguió los acontecimientos, posiblemente apoyado por información que le era enviada directamente desde México y, cuando el imperio fracasó, Cantú escribió una versión justificativa que apareció en su ya citada Historia de treinta años, suerte de continuación de la Historia universal.

Ello debía suscitar la respuesta del gobierno mexicano. Primeramente fue la pluma de Benito Juárez Maza, hijo del prócer y delegado mexicano en París, quien publicó en Le Nouveau Monde una carta donde denunciaba epítetos y calumnias como las de que su padre era jefe de una cuadrilla de bandoleros, que había querido vender a Estados Unidos el Istmo de Tehuantepec y hasta puesto precio a la entrega del cadáver de Maximiliano. Agregó detalles y ciencia el liberal español José Román Leal, residente en México, en artículos que después recogió en libro, donde descargaba ahí a Juárez y a los liberales de las acusaciones: "Sepa el señor Cantú que México no es un pueblo de bandoleros ni anarquistas ni siquiera demagogos". Envolvía su argumentación en extensos comentarios políticos y filosóficos, le exigía "el juicio y el método que enseña en los teoremas de sus discursos, de cuya aplicación se olvida, sobre todo, al ocuparse de la historia de México". No sin recordar que había encontrado a Cantú en Europa (LEAL 1886, p. 278, 187).

Más tarde fue el mismo gobierno mexicano quien encargó a Pedro Santacilia una refutación de mayor peso en la forma de un folleto que fue publicado en castellano, francés, inglés y portugués. No se dejaban de reconocer méritos: "las altas dotes que distinguen y recomiendan al historiador César Cantú le han valido de justicia la merecida reputación de que goza en el mundo civilizado; y nosotros que fuimos siempre sus sinceros admiradores, somos hoy los primeros en reconocer ese juicio universal". No le enrostraba mala fe, pero "es importante hacer constar que César Cantú fue amigo personal y profesor de Maximiliano, que obtuvo de éste nombramientos honoríficos y comisiones para un trabajo de instrucción pública y que no estaba por lo mismo en condiciones de completa 
independencia"; por lo demás, era conservador y admitía que escribía sobre hechos cercanos en el tiempo "sin pruebas" (JUÁREZ Y CÉSAR CANTÚ 1885).

Respuesta insuficiente, de estilo demasiado cortesano, alegaba un crítico más severo, que no podía tolerar los cargos hechos a Benito Juárez de traidor a la patria, vulgar ambicioso y jefe de bandidos, expresados por "un hombre de letras que, mala o legítimamente, goza de nombradía como historiador y aun como filósofo". Con mala fe,

compilador más paciente y perseverante que entendido, desde el tomo II de su Historia universal hasta sus últimos trabajos historiólogos, toda su filosofía y todo su ideal consisten en hacer resaltar las sublimidades del catolicismo, para concluir que el papado es la institución más adecuada a la realización del progreso humano.

De opiniones incoherentes, liberal y papista, "jesuita disfrazado de liberal; escribe y trabaja para su Orden; pero con tan corto alcance que si falsea los principios de la escuela liberal, no por eso afirma los dogmas de la ortodoxia". Áulico de Maximiliano, lo llama en otra parte (SÁNCHEZ MÁRMOL 2011, t. 3, p. 317 y 379 y ss., discurso de 1865 y "Ave Patria", de 1889).

Tuvo Cantú que defenderse; mandó al citado Desteffanis, que enseñaba en Uruguay, una carta para que hiciera publicar, donde se justificaba alegando que se trataba de hechos recientes para los cuales había elegido fuentes que le habían parecido confiables, aduciendo que era necesario que se calmaran las pasiones (DESTEFFANIS, 1885). El episodio no le restó admiradores, pero algunas frases de la polémica muestran que ya para entonces su obra, que nunca había sido indiscutida, hallaba críticos entre un público latinoamericano que paulatinamente se había hecho más conocedor del mundo y de los libros. 


\section{El ocaso}

El prestigio de Cantú entre los estudiosos europeos nunca había alcanzado altos niveles y no sobrevivió a su siglo, como puede verse en los panoramas de historia de la historiografía que comenzaron a aparecer. Por italiano, por escribir tempranamente y quizás porque cojeaba de la misma pata, el conde, cantor, poeta y sanscritista Angelo de Gubernatis lo incluyó con elogio en la sección sobre historiografía de su amplia Historia de la literatura universal (1882-1885), también traducida al castellano y también frecuentada entre nosotros aunque no tanto como la de Cantú. Compilada bajo el fascismo, la Enciclopedia Italiana lo alaba ya con reservas, ${ }^{9}$ pero el muy meticuloso suizo Eduard Fueter (Historia de la historiografía moderna, 1913) ni lo nombra; el inglés Gooch algo dice, pero es esto: "no era un gran erudito ni un artista. Era prolijo y superficial, y demuestra poca penetración histórica; pero poseía un talento nada común para la popularización" (GOOCH [1913] 1942, p. 438-439). Otro recuento, el de su coterráneo Benedetto Croce, fue más feroz, lanzándole, entre otros denuestos: todo repite, mejor dicho eructa veloz y afanosamente, en nada se detiene, de todo charla, confuso e incoherente, reaccionario disfrazado de liberal, y ni siquiera eso, un vanidoso, un enojón, autor de un cambalache. ${ }^{10}$ No lo quería, evidentemente, pero no se muestra injusto.

Siguieron pasando las décadas. El estadounidense Harry Elmer Barnes incluía su obra en una apretada lista de historias universales, nombrándolo entre quienes popularizaron la historia de Italia; también divulgador de poco mérito lo consideraban Thompson y Holm ("Scholars may look for the little accuracy and less originality in a work of such compass, but it was widely known and long a popular book of reference for Italians [...] in general superficial, written with an eye to the public, and an occasional spurt of venom") (BARNES 1962, p. 172, 191, 221; THOMSON; HOLM 1942, v. 2, p. 612). Percibo un ligero desdén
8 Gubernatis (1943) [es el tomo xi de su Historia de la literatura, 1883-1885], $p$. 215-216: "se apresta a redactar su Historia universal, nueva por su concepto y ejecución, y amplia al par que rápida, en cuyas páginas, si bien se han advertido muchos errores, tres generaciones de italianos $y$ muchos extranjeros han sacado preciosas enseñanzas".

9 "Ingiusto non riconoscergli, ed erroneo sarebbe negare ad ogni suo libro un valore anche scientifico, oppure letterario", "di gran lunga superiore a quello dei volgari compilatori" "vi è assai d'imprecisione, di tendenze personali, di malizie, volontarie o involontarie che fossero, contro i vivi a proposito dei morti, e contro i morti a proposito dei vivi"; méritos aunque "non è un pensatore profondo ne uno storico accurato" De esta forma, Mazzoni (1930), matiza los juicios.

(CONT.) 
en estos viejos repertorios anglosajones: podía servir para italianos como mucho. ${ }^{11}$ Después, el silencio, fuera de las obras de inspiración católica. ${ }^{12}$

Tales juicios necesariamente refluirían sobre nuestros autores, que ya habían venido señalando cautamente las deficiencias de la obra de Cantú. Al compilar su Historia universal de 1865, Juan Vicente González no mostraba entera satisfacción con Cantú, lo vimos. Otros se concentraron en cuestiones locales, donde la pifia era evidente: al publicar Felipe Tejera, en París, su Venezuela pintoresca e ilustrada (1875), justificaba el esfuerzo aduciendo los incomprensibles errores hallados en la bibliografía europea: "El más célebre historiador moderno, Cantú, en su Historia universal hace nacer al Libertador Simón Bolívar en 1780" (TEJERA 1875, t. 1, p. vi). Alejamiento prudente que también manifestaba Rafael María Merchán: "la Historia universal de César Cantú tiene gran reputación y no se debe hablar de ella sino con respeto pero, como en otra ocasión lo dijimos, contiene errores" (MERCHÁN 1886).

Otros apuntaban al lado religioso, cuando ya muchas críticas en ese sentido habían dejado de ser peligrosas y se podía afear a "un autor que a pesar de su talento y erudición, no tiene inconveniente en dar principio a su Historia universal con la creación del mundo conforme al Antiguo Testamento" (GARCÍA GRANADOS [1910] 1992, p. 323-324). Podían estar semejantes ataques, en realidad, dirigidos a otros trabajos: su libro Gli eretici d'Italia, "obra parcial y mediocre que envenenó las fuentes de la investigación en España y en Hispanoamérica durante medio siglo", había inspirado los Heterodoxos españoles de Menéndez Pelayo (SANÍN CANO [1912] 1987, p. 160), por lo cual la polémica en torno a la obra del santanderino involucró al lombardo, defendido por católicos como Gómez Restrepo, que no consideraba tan malos los Eretici (GÓMEZ RESTREPO 2001 , p. 24 y 27$)$.

Después, las observaciones ya se dirigieron al conjunto de la obra, empezando por el estilo: una inteligencia criolla cada vez más enterada podía señalar que en América se leía poco y 
sólo libros al estilo de "la pomposa y falsa erudición de Cantú".13 Continuando su ataque contra Menéndez y Pelayo, Sanín Cano veía mal que éste recomendara "el entusiasmo verbal de César Cantú como desiderátum de estilo" "en una época en que escribieron Renan, Ruskin, Turgueniev, los Goncourt, Flaubert y Walter Pater". Después embistieron contra su método: "organizadores de datos históricos de mediana inteligencia pero de voluminosa erudición como César Cantú", clasificaba Justo Sierra (1948, p. 32). Al hacer la crónica de unas conferencias de Cantú en Milán, José Martí hablaba del numeroso público que iba a oír al "trabajador maravilloso, que ha puesto en forma bella todos los trabajos de los hombres, al narrador fluidísimo, que pone magia y brillo en cuanto narra", elogio habitual al que sin embargo agregaba que su libro, "con haber parecido obra de investigador pasmoso ha medio siglo, parece ahora en uno y otro trecho obra de estudiante adornado o de poeta perezoso, que cree que lleva el mundo en sí y dado el regalo de mirarse, no ve el mundo" (MARTÍ [1882] 1975).

Para entonces ya había estallado la polémica en torno a Juárez. Como fue dicho, fueron obras posteriores a la Historia universal el objeto de escándalo y tales obras no tuvieron el peso de ésta: el Compendio es árido, los Treinta años, de vigor menguado, juzgaba el padre Federico González, cuya gran admiración por Cantú ya fue apuntada (GONZÁLEZ SUÁREZ 1892). Los epítetos de Benedetto Croce se abrieron camino hasta nuestras letras: Alfonso Reyes se hacía eco y, al recordar la presencia del italiano en la biblioteca de su padre, expresaba alguna concesión a sus máximas, a la amenidad de sus escenas, pero agregaba que "el conjunto es un torbellino en el vacío" y "en todo caso, ha llegado para éste la hora del olvido", cuando en las ferias de libros su historia se arrumba "entre esas cosas que nadie compra" (REYES [1918] 1958, p. 363-364).

Parecería que Reyes trasunta como otros nostalgia por esa época en que obligadamente figuraba Cantú en las bibliotecas hogareñas, pero también hay en él cierta burla de la ingenuidad historiográfica de aquellas familias de antaño. Se había

\section{(CONT.)}

12 No tiene su entrada en los repertorios como Boyd (1999) o Cannon (1988); no lo mencionan Breisach (1994); Burrow (2007); Iggers, Wang, Mukherjee (2017); Woolf (2011).

13 Prólogo de Manuel Murillo Toro que cita, para refutarlo, Caro ([1882] 1962). 
convertido el viejo monumento en el refugio de las medianas inteligencias que buscaban un recurso fácil para entender la marcha de los siglos: en cierto cuento de Horacio Quiroga hay un indio correntino que aprende a leer y progresa de forma autodidacta: "tenía una cierta cultura adquirida a hurtadillas, bastante superior a la que demostraba, y en los últimos tiempos había comprado la Historia universal de César Cantú. Pero esto lo supimos después, en razón del sigilo con que ocultaba de las burlas ineludibles sus aspiraciones a doctor" (QUIROGA 1981 , p. 199). Pretensiones como las del hacendado y general ecuatoriano que "se sabía de memoria el célebre discurso a la juventud italiana" de Cantú, cuyos libros aplastaban a los demás en los estantes "con su hidropesía numérica" (TERÁN [1940] 1964, p. 60).

Referencias en clave destinadas a individualizar a lectores de gustos e información envejecidos, que se dejaban impresionar por el aparato de la edición. Atrás de la colección de Cantú encuentra la mayorala Elmira una tosca bomba de fabricación casera destinada al pretencioso dictador tropical de la novela EI recurso del método, ambientada en torno a la primera Guerra Mundial (CARPENTIER 1974, p. 182). Años más, años menos, son también el escenario del cuento de Quiroga, de la novela de Terán y de las aventuras del druso Abenjaldún, protagonista de uno de los cuentos de Bustos Domecq, quien tiene "una biblioteca fenómeno" donde figura Cantú en su traducción de 1927; sin embargo el elenco de los otros títulos revela al lector de la época que la tal biblioteca fenómeno era en realidad un amasijo informe de libros insignificantes o anticuados.

A hurtadillas, como el indio correntino, quizás lo seguían leyendo; en todo caso porque no había otra cosa para allegar cierta documentación y la obra de Cantú se mantenía como la bibliografía más asequible: hace poco se la ha citado como ejemplo de la desactualización de las bibliotecas públicas de Río de Janeiro y de otras ciudades brasileñas, que sobre historia general sólo albergaban traducciones portuguesas de colecciones con muchos volúmenes pero de valor discutible, 
como las de Cantú y Wilhelm Oncken (aunque a esta última, de varios autores, se le reconocían colaboraciones importantes, como la de Eduard Meyer) (CARDOSO 2011, p. 452). Mala, pero por lo menos estaba; por ello, aunque se burlaran, Borges y Bioy Casares usaron a Cantú para ciertos datos de su Libro del cielo y del infierno. ${ }^{14}$ Vemos que lo cita Ezequiel Martínez Estrada y que lo cita la bestia negra de los tres, Juan Domingo Perón (éste y otros ejemplos dados me hacen pensar que debía de gustar a los militares), quien con toda seriedad documentaba su afición a los clásicos, a Plutarco, que había conocido primeramente por medio de Cantú, a quien confesaba deberle "el sentido universalista y antidogmático de ese aprendizaje. Muchas veces he releído con emoción los comentarios marginales que puse sobre los diez gruesos tomos de pasta española que componen su Historia y que recibí como legado de mi padre" (PAVÓN PEREYRA 1986, p. 61).

\section{Consideraciones finales}

El recuento de casos particulares podría ampliarse. Bastaría incluir las muchas notas a pie de página; buscando más, ejemplificaciones históricas que tienen su fuente en Cantú. Faltarían, para mayor seguridad, más datos duros para demostrar su influencia: junto a la cantidad de ediciones que se mencionó, también los tirajes, la enumeración de bibliotecas públicas que lo incluían, su inclusión en planes de estudio. Creo sin embargo que es hora de recapitular: se trataba de mostrar la influencia de un autor hoy poco conocido y nunca demasiado estimado por la academia. Se pudieron extraer algunas conclusiones, hasta aquí desmigajadas y en los párrafos siguientes resumidas.

Llegó Cantú a ofrecer una de las muchas historias universales que se estaban ofertando desde Europa. A diferencia de otras quizás más confiables - por ejemplo las que del alemán se estaban traduciendo al italiano en esos tiempos-, la suya contenía una interpretación adecuada al momento latinoamericano: con abundancia de información que en otros

14 Varias páginas, en efecto, sobre la escatología de diverSOS pueblos (BORGES; BIOY CASARES [1955] 1999, p. 112 y ss). 
sitios no encontrábamos, especialmente en lo referente a áreas extraeuropeas, con inclusión de la historia precolombina, colonial y hasta moderna de nuestros países, con reflexiones que nos halagaban, todo envuelto en una exégesis que podía complacer tanto a los liberales como a los conservadores.

A los primeros a pesar del episodio ligado a Benito Juárez, que los ofendió pero no tanto como para negar la admiración. Los conservadores tuvieron un poco más de preferencia y ésta les duró más tiempo. Con los años, sin embargo, se vio que la ciencia del piamontés no era tanta como se decía, ni tan exacta, ni mesurada. Como señal de la mayor seguridad latinoamericana en conocimientos universales, empezaron a oírse críticas y hasta burlas. En parte era por la mayor conciencia de que el admirado Cantú no era tomado muy en serio por los autores más respetados, los del norte de Europa. En parte, reflejo de críticas que sus mismos coterráneos le dirigieron.

Estas últimas críticas se habían ya formulado desde el comienzo: no existe en su obra investigación sobre fuentes primarias, prima una recopilación indiscriminada, con pretensiones infundadas de erudición que los expertos desenmascaran fácilmente; hay desequilibrio, parcialidad, entendimiento equivocado, apresuramiento y generalización indebida y, de ahí, errores numerosos.

Bajó de categoría Cantú, al nivel de un divulgador para legos. Aunque siguió siendo referencia de mucho escrito erudito, ya por pudor se lo citaba menos. Tampoco critiquemos demasiado: se está yendo, pero, si en las librerías de viejo todavía se agazapan sus volúmenes, en las de nuevo pululan otros cantúes bajo la forma de manuales, de colecciones. Hay programas culturales, páginas de Internet, que han tomado el relevo suministrándonos la vieja historia eurocéntrica, moralista y prejuiciada en tomos bien encuadernados, en programas amigables, con ilustraciones fascinantes, con datos y con la apariencia del rigor, dirigiéndose especialmente a nuestro público latinoamericano. 


\section{REFERENCIAS}

ARGUEDAS, Alcides. La danza de las sombras: literatura e historia. In: ARGUEDAS, Alcides. Obras completas. Preparación, prólogo y notas de Luis Alberto Sánchez. Madrid-México-Buenos Aires: Aguilar, 1959, t. 1, p. 630631.

ARZE, José Roberto. Análisis crítico del "Bolívar" de Marx. Carta-prólogo del dr. Ángel Francisco Brice. La Paz: Anthropos, 1998.

BARNES, Harry Elmer. A history of historical writing. Second and rev. ed. New York: Dover, 1962.

BELAUNDE, Víctor Andrés. Trayectoria y destino: memorias. Estudio preliminar de César Pacheco Vélez. Lima: Ediventas, 1967.

BERENGO, Marino. Cesare Cantú. In: Dizionario biografico degli italiani. Roma: Istituto dell' Enciclopedia Italiana, 1975, v. 18. p. 336-344.

BLANCO FOMBONA, Rufino. Ensayos históricos. Prólogo Jesús Sanoja Fernández, sel. y cronología Rafael Ramón Castellanos. Caracas: Biblioteca Ayacucho, 1981.

BORGES, Jorge Luis; BIOY CASARES, Adolfo. Libro del cielo y del infierno (1955). Buenos Aires: Emecé, 1999.

BOYD, Kelly (org). Encyclopedia of history and historical writing. London \& Chicago: Fitzroy Dearborn, 1999.

BREISACH, Ernst. Historiography: ancient, medieval \& modern. Chicago: University of Chicago Press, 1994.

BURROW, John. Historia de la historia: de Heródoto al siglo xx. Barcelona: Crítica, 2007. 
CANNON, John et al. The Blackwell dictionary of historians. Oxford: Basil Blackwell, 1988.

CANTÚ, César. Los últimos treinta años: continuación de la Historia Universal. Trad. D. G. Aguado de Lozar, aprobada por el autor. Paris: Garnier, 1881.

CANTÚ, Cesare. Prefazione all'edizione italiana (marzo 1864). In: CHEVALIER, Michele. Il Messico. Milano: Corona e Caimi, 1878.

CANTÚ, Francesca. 'America' e 'Spagna' nella Storia universale. In: Cesare Cantú e "L'età che fu sua". Giornata di studi, Milano, Biblioteca Ambrosiana, 2005, interventi, a cura di Claudia Crevenna. Disponible en: http://www.cesarecantu.it/cesare-cantu-e-leta-che-fusua-2004-2005/. Consultado en: 9 agosto 2020.

CARBALlO, Emmanuel. Protagonistas de la literatura mexicana (1965). México: SEP-Ediciones del Ermitaño, 1986.

CARDOSO, Ciro Flamarion. Brazilian historical writing and the building of a nation. In: MACINTYRE, Stuart; MAIGUASHCA, Juan; PÓK, Attila Pók (orgs.). The Oxford history of historical writing. New York etc: Oxford University Press, 2011, vol. 4, 447-462.

CARO, Miguel Antonio. Recuerdos y rectificaciones (a $L a$ América de Madrid) (1882). In: CARO, Miguel Antonio. Obras, tomo 1. Estudio preliminar por Carlos Valderrama Andrade. Bogotá: Instituto Caro y Cuervo, 1962. p. 958972.

CARPENTIER, Alejo. El recurso del método. México: Siglo XXI, 1974.

CAVRIANI, Marco. Antonio Minelli. In: Dizionario biografico degli italiani. Roma: Istituto dell' Enciclopedia Italiana, 2010. v. 74. 
CERRÓN-PALOMINO, Rodolfo. Sobre el carácter espurio de la trilogía moral incaica. In: REGALADO, Liliana; HERNÁNDEZ, Francisco (orgs). Sobre Los Incas. Lima: Instituto Riva Agüero/Pontificia Universidad Católica del Perú, 2011. p. 67-87.

CORTÉS, José Domingo. Diccionario biográfico americano. Paris: Lahure, 1875, s.v.

CROCE, Benedetto. Storia della storiografia italiana nel secolo decimonono. Terza edizione riveduta. Bari: Gius. Laterza e Figli, 1947.

DESTEFFANIS, Luis D. Cesare Cantú. In: Anales del Ateneo del Uruguay, año 4, t. 9, 1885.

DEVOTO, Fernando. Historia de los italianos en Argentina. $2^{\mathrm{a}}$ ed. Buenos Aires: Biblos, 2006.

DIHIGO Y MESTRE, Juan M. Un orientalista cubano: Francisco Mateo de Acosta y Zenea, discurso ... 1932. La Habana: El siglo xx, 1932.

ENCINA, Francisco A. Resumen de la historia de Chile. Redacción, iconografía y apéndices de Leopoldo Castedo. Santiago: Zigzag, 1954.

FILIPPI, Alberto (Dir.). Bolívar y Europa en las crónicas, el pensamiento político y la historiografía. Caracas: Presidencia de la República, 1986.

FINCH, James Austin. Cesare Cantù. In: Catholic World, v. 43, n. 256, p. 525-534, 1886.

FITZSIMONS, Matthew A.; PUNDT, Alfred G.; NOWELL, Charles $E$. The development of historiography. Harrisburg, PENN: The Stackpole Company, 1954.

FLORESCANO, Enrique. La función social de la historia. México: fce, 2012. 
GARCÍA CALDERÓN, Francisco. Riva Agüero, compañero de generación (1949). In: HAMPE MARTÍNEZ, Teodoro (org.). América Latina y el Perú del Novecientos: Antología de textos, compilación, introducción y notas de Teodoro Hampe Martínez. Lima: Universidad Mayor de San Marcos, 2003.

GARCÍA GRANADOS, Ricardo. El concepto científico de la historia (1910). In: ORTEGA Y MEDINA, Juan A. (org.). Polémicas y ensayos mexicanos en torno a la historia. Notas bibliográficas e índice onomástico por Eugenia W. Meyer [1970]. 2a. edición. México: unam, 1992. p. 315-370.

GARCÍA ORTIZ, Laureano. Las viejas librerías de Bogotá en 1883. In: GARCÍA ORTIZ, Laureano. Discursos académicos, Bogotá: Biblioteca de la Presidencia de la República, 1932. p. 21-39.

GÓMEZ RESTREPO, Antonio. Epistolario de Antonio Gómez Restrepo con escritores españoles. Ed., pres. y notas de Mario Germán Romero. Bogotá: Instituto Caro y Cuervo, 2001.

GONZÁLEZ SUÁREZ, Federico. César Cantú: una lección en la clase de historia. Anales de la Universidad de Quito, serie 6, n. 43 p. 131-145, 1892.

GONZÁLEZ SUÁREZ, Federico. Memorias íntimas. Discurso de Mariana de Jesús. Manifiesto a los ecuatorianos. Intr. de Carlos Manuel Larrea, Puebla: José M. Cajica, 1969.

GONZÁLEZ, Juan Vicente. Manual de historia universal, Caracas: Rojas Hermanos, 1863.

$\mathrm{GOOCH}$, George P. Historia e historiadores en el siglo xIx (1913), México: FCE, 1942.

GROOT, José Manuel. Réplica al ministro presbiteriano H. B. Pratt. Bogotá: Imprenta de El Tradicionista, 1876. 
GUBERNATIS, Ángel de. Historia de la historiografía universal. Pról. de Rómulo Carbia y epílogo de Juan F. Turrens. Buenos Aires: CEPA, 1943.

GUIANCE, Ariel. La historiografía española y el medievalismo americano: Sánchez-Albornoz, Américo Castro y la construcción de la identidad nacional a través de la Edad Media. In: GUIANCE, Ariel (org.). La influencia de la historiografía española en la producción americana. Valladolid: Instituto Universitario de Historia Simancas/ Marcial Pons Historia, 2011. p. 25-58.

HARBSMEIER, Michel. World histories before domestication. Culture and History, 5, p. 93-131, 1989.

HENAO RESTREPO, Darío. El mundo de Nay y Ester. Poligramas, 3, p. 9-28, 2005.

IGGERS, Georg G.; WANG, Q. Edward; MUKHERJEE, Supriya (orgs.). A global history of modern historiography. $2^{\text {nd }}$ ed. London/New York: Routledge, 2017.

JUÁREZ Y CÉSAR CANTÚ: refutación de los cargos que hace en su última obra el historiador italiano contra el Benemérito de América. México: Imprenta del Gobierno Federal en Palacio, 1885.

KURBAN, Taufik. Os syrios e lebaneses no Brazil. São Paulo: Libraria Freitas Bastos, 1933.

LARIOS MENGOTTI, Gonzalo. Abdón Cifuentes en Europa. Anuario de Historia de la Iglesia en Chile, v. 29, p. 85109, 2011.

LARRAINZAR, Manuel. Algunas ideas sobre la historia y manera de escribir la de México (1865). In: ORTEGA $Y$ MEDINA, Juan A. (comp.). Polémicas y ensayos mexicanos en torno a la historia. Notas bibliográficas e índice onomástico por Eugenia W. Meyer [1970]. 2a edición. México: UnAm, 1992. p. 142-255. 
LASTARRIA, José Victorino. Investigaciones sobre la influencia social de la conquista i del sistema colonial de los españoles en Chile (1843). In: LASTARRIA, José Victorino. Estudios históricos. Santiago: Imprenta, litografía y encuadernación Barcelona, 1909. v. 7.

LATCHAM, Ricardo A. Psicología del caballero chileno (1930). In: Ricardo A. Latcham (1903-1965), Santiago: Atenea, 1903. p. 146-150.

LEAL, José Román. México constitucional: refutación fundamental ante la razón de la historia, de los errores vigentes de César Cantú y de las injurias y calumnias levantadas contra México por los libelistas. México: Imprenta de Mena y Vilaseca, 1886.

LOAIZA CANO, Gilberto. La expansión del mundo del libro durante la ofensiva reformista liberal: Colombia, 1845-1886. In: ACOSTA PEÑALOZA, Carmen Elisa; AYALA DIAGO, César Augusto; CRUZ VILLALOBOS, Henry Alberto (orgs.). Independencia, independencias $y$ espacios culturales: Diálogos de historia y literatura. Bogotá: Universidad Nacional de Colombia, 2009. p. 25-64.

MARTÍ, José. Escenas europeas: Italia. In: MARTÍ, José. Obras completas. La Habana: Editorial de Ciencias Sociales, 1975. v. 14 ,.p. 393-400.

MAZZONI, Guido. Cesare Cantú. In: Enciclopedia Italiana di Scienze, Lettere ed Arte. Roma: Istituto per I'Enciclopedia Italiana, 1930. v. 8. p. 809-810.

MELO ARAÚJO, André de. Tradução ilustrada: imagens da História Universal inglesa e de suas edições europeias no século XVIII. História da Historiografia, n. 26, p. 69100, 2018. 
MERA, Juan León. Libros prestados (1862). In: MERA, Juan León. Tijeretazos y plumadas: artículos humorísticos, precedidos de una carta-prólogo de José de Alcalá Galiano. Madrid: Est. Tip. de Ricardo Fé, 1903. p. 99-111.

MERCHÁN, Rafael M. La política en la historia. In: MERCHÁN, Rafael M. Estudios críticos. Bogotá: Imprenta de la Luz, 1886. p. 291-368.

MILLÁN DE BENAVIDES, Carmen. Anacronismos y persistencias: la Historia universal de Cesare Cantú. In: RINCÓN, Carlos Rincón; MOJICA, Sarah de; GÓMEZ, Liliana (orgs.). Entre el olvido y el recuerdo: iconos, lugares de memoria y cánones de la historia y la literatura en Colombia. Bogotá: Pontificia Universidad Javeriana, 2010. p. 239-253.

MOLINA ARGÜELLO, Carlos. La enseñanza de la historia en Nicaragua. México: IPGH, 1953.

MOLINA ENRÍQUEZ, Andrés. Los grandes problemas nacionales [1909] [y otros textos, 1911-1919]. Prólogo de Arnaldo Córdova. México: Era, 1978.

MONTALVO ANTE SUS ADMIRADORES EXTRANJEROS. Ambato: Imprenta y Encuadernación Nacionales, 1911.

MONTALVO, Juan. Mercurial eclesiástica. Libro de las vanidades y un vejestorio ridículo. Madrid: Editorial América, sf.

MORENO, Ezequiel. Epistolario del beato ... y otros agustinos recoletos con Miguel Antonio Caro y su familia. Compilación, introducción y notas de Carlos Valderrama Andrade. Bogotá: Instituto Caro y Cuervo, 1983.

ODDONE, Juan Antonio. La historiografía uruguaya en el siglo xIx: apuntes para su estudio. Revista Histórica de la Universidad de Montevideo, núm. 1, p. 3-37, 1959. 
ORSI, Pietro. Cesare Cantú. Revue Historique, t. 58, fasc. 2, p. 382-384, 1895.

OSIO, Bernardino. Le lettere di Cesare Cantù a Pedro II imperatore del Brasile. In: Cesare Cantú e "L'età che fu sua". Giornata di studi, Milano, Biblioteca Ambrosiana, 2005, interventi, a cura di Claudia Crevenna. Disponible en: http://www.cesarecantu.it/cesare-cantu-e-leta-che-fusua-2004-2005/. Consultado en: 9 agosto 2020.

PÁEZ, José Antonio. Memorias, autobiografía. Madrid: Editorial América, s.f.

PASAMAR, Gonzalo, Formas tradicionales y formas modernas de la "historia del presente". Historia Social, n. 62, p. 147-169, 2008.

PAVÓN PEREYRA, Enrique. Perón tal como fue. Buenos Aires: CEAL, 1986.

PAZ SOLDÁN, Mariano Felipe. Historia del Perú independiente, Primer periodo 1819-1822. Lima: s.ed., 1868.

PELLESCHI, Giovanni. Eight months on the Gran Chaco of the Argentine Republic. London: Sampson Low, Marston, Searle \& Rivington, 1886.

PEROLARI MALMIGNATI, Pietro. Il Peru e i suoi tremendi giorni (1878-1881): pagine d'uno spettatore. Milano: Fratelli Treves, 1882.

QUIROGA, Horacio. La cámara oscura. In: QUIROGA, Horacio. Cuentos. Selección y prólogo de Emir Rodríguez Monegal, cronología de Alberto F. Oreggioni. Caracas: Biblioteca Ayacucho, 1981. 
RAMÍREZ, Ignacio. Geografía elemental del estado de Guanajuato (1905). In: RAMÍREZ, Ignacio. Obras completas. México: Centro de Investigación Científica Ing. Jorge L. Tamayo, 1988, vol. 6.

REYES, Alfonso. César Cantú (1918). In: REYES, Alfonso. Obras completas. México: fce, 1958. t. 7. p. 363-364.

REYES, Alfonso. Oración del 9 de febrero (1930). In: REYES, Alfonso. Obras completas, México: fce, 1990. t. 24. p. 2552.

RIVA AGÜERO, José de la. Carácter de la literatura del Perú independiente (1905). Intr. general de Víctor Andrés Belaunde... . In: RIVA AGÜERO, José de la. Obras completas. Lima: Pontificia Universidad Católica del Perú, 1962. v. 1.

RODRÍGUEZ PRAMPOLINI, Ida. La historia y sus dones. Crónica, 13-IX, 2003.

ROIG, Arturo Andrés. La filosofía de la historia de Benjamín Sánchez. Cuyo, Mendoza, v. 6, p. 177-181, 1970.

SÁNCHEZ MÁRMOL, Manuel. Obras completas. Tabasco: Universidad Juárez Autónoma de Tabasco, 2011.

SANÍN CANO, Baldomero. Menéndez Pelayo (1912). In: SANÍN CANO, Baldomero. El oficio de lector. Compilación, prólogo y cronología Gustavo Cobo Borda. Caracas: Biblioteca Ayacucho, 1987. p. 157-161.

SCHWAB, Raymond. La Renaissance orientale. Paris: Payot, 1950.

SIERRA, Justo. Historia de la Antigüedad. In: SIERRA, Justo. Obras completas. Tomo 10, ed. establecida por Edmundo O'Gorman. México: UNAM, 1948. 
STUCHTEY, Benedikt; FUCHS, Eckhardt. Introduction. Problems in writing of world history: Western and nonWestern experiences, 1800-2000. Apud. Writing world history 1800-2000. Oxford/New York: German Historical Institute London, 2003. p. 1-44.

SUBERCASEAUX, Bernardo. La cultura en la época de Balmaceda (1880-1900). In: VVAA, La época de Balmaceda. Santiago de Chile: Dirección de Bibliotecas, Archivos y Museos, 1992.

TEJERA, Felipe. Venezuela pintoresca e ilustrada. Paris: Librería Española de E. Denné Schmitz, 1875.

TERÁN, Enrique. El cojo Navarrete (1940). Quito: Casa de la Cultura Ecuatoriana, 1964.

THOMPSON, James Westfall; HOLM, Bernard J. A history of historical writing. New York: Macmillan, 1942.

VEGA, Juan José. Historia y evolución del 'ama sua'. In: VEGA, Juan José. Páginas de la historia del Perú. 2012. Disponible en: http://batiburriloacg.blogspot.com/2012/09/ historia-y-evolucion-del-ama-sua.html. Consultado en: 9 agosto 2020.

VICUÑA MACKENNA. Benjamín, Pájinas de mi diario durante tres años de viajes 1853-1854-1855. Santiago: Imprenta del Ferrocarril, 1856.

WOOLF, Daniel. A global history of history. Cambridge University Press, 2011. 
NOTA DEL AUTOR

\section{Hernán G. H. Taboada}

haroldo@unam.mx

Universidad Nacional Autónoma de México

Centro de Investigaciones sobre América Latina y el Caribe

Ciudad de México

México

\section{DIRECCIÓN POSTAL}

Hernán G. H. Taboada

Universidad Nacional Autónoma de México

Ciudad Universitaria

Centro de Investigaciones sobre América Latina y el Caribe

Piso 8 Torre II de Humanidades

04510

Ciudad de México

México

\section{FINANCIACIÓN}

No se declaró financiación.

\section{CONFLICTO DE INTERESES}

Sin conflicto de interés declarado.

\begin{abstract}
Copyright
2020 História da Historiografia: International Journal of Theory and History of Historiography. EEste es un artículo de acceso abierto distribuido bajo los términos de la licencia Creative Commons ReconocimientoNo ComercialSinObraDerivada 4.0 International.
\end{abstract}

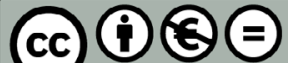

